\title{
ARTICLE
}

\section{Analysis of Radioactive Cesium-Enriched Particles and Measurement of Their Distribution in Marine Sediment Near Fukushima Daiichi Nuclear Power Plant}

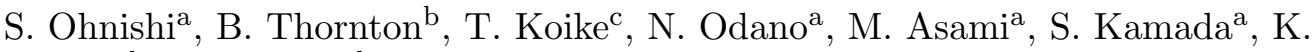 \\ Nagano ${ }^{\mathrm{b}}$, and T. Ura ${ }^{\mathrm{b}}$ \\ anational Maritime Research Institute, Japan, 6-38-1 Shinkawa, Mitaka, Tokyo, Japan \\ ${ }^{b}$ Institute of Industrial Science, the University of Tokyo, 4-6-1 Komaba, Meguro-ku, Tokyo, \\ Japan ${ }^{\mathrm{c}}$ Mitsui Engineering \& Shipbuilding Co. Ltd., 1-1-5 Tsutsujigaoka, Akishima, Tokyo, \\ Japan
}

\section{ARTICLE HISTORY}

Compiled February 12, 2021

\begin{abstract}
Cesium-enriched particles released from the Fukushima Daiich Nuclear Power Plant (NPP1) exist in the Fukushima coastal waters and offshore, and they possibly affect the wide-area distribution of the radioactive cesium measured by the towed spectrometer. Therefore, the distribution of them in marine sediment was measured near NPP1 in November, 2016. We scanned the seafloor using a remotely operated vehicle (ROV) equipped with a $\mathrm{NaI}(\mathrm{Tl})$ scintillation detector. The sediment samples were obtained on the survey line by the ROV's suction-type sampler. Five cesium particles, with diameters of approximately $400 \mu \mathrm{m}$, were isolated from the samples. The radioactivity of ${ }^{137} \mathrm{Cs}$ was less than $360 \mathrm{~Bq}$, and no nuclides other than ${ }^{134} \mathrm{Cs}$, ${ }^{137} \mathrm{Cs}$, and natural radioactive ones were found from gamma-ray spectroscopy. In the particles, titanium and calcium were commonly detected by energy-dispersive X-ray spectrometry. We also estimated the particles' presence from the change in the total counting rate of the scintillation detector. The average particle density is found to be $3.45 \times 10^{-2} \mathrm{~m}^{-1}$ at most. The average increase in the counting rate directly above the cesium-enriched particles in the sediment was less than double. Therefore, the effect of such particles on the distribution of radioactive cesium is limited.
\end{abstract}

\section{KEYWORDS}

sediment; radioactive cesium; cesium-enriched particle; Tohoku; Fukushima; ROV; underwater measurement

\section{Introduction}

A large amount of radioactive materials were emitted into the environment by the severe core damage accident of Fukushima Daiichi Nuclear Power Plant (NPP1) caused by the March, 2011 earthquake. By a comparison of atmospheric and oceanic dispersion simulations with the observed data, $1.3 \times 10^{16}$ and $3.5 \times 10^{15} \mathrm{~Bq}$ of ${ }^{137} \mathrm{Cs}$ were estimated to have been released into the atmosphere and the ocean, respectively[1]. It is also suggested by preliminary numerical analysis that the release of $1 \mathrm{TBq} /$ day or more continued for about 20 days after that[2]. The ${ }^{137} \mathrm{Cs}$ release from the plant harbor 
became 93.2 GBq/day in summer 2011 and $8.1 \mathrm{GBq} /$ day in summer 2012[3]. Then, it decreased to $12 \sim 14 \mathrm{GBq} /$ month (equivalent to $0.40 \sim 0.47 \mathrm{GBq} /$ day) in June 2018[4]. Radioactive cesium in seawater has diffused rapidly[2], and the current radioactive cesium concentration level is lower than the detection limit $\left(\sim 0.8 \mathrm{~Bq} / \mathrm{L}\right.$ for $\left.{ }^{137} \mathrm{Cs}\right)$ even in the proximity of the port of NPP1[5]. By contrast, the concentration in marine sediment remains high[6]. Therefore, our group had measured radioactive materials in marine sediment in Tohoku waters with a towed spectrometer and multiple corers [7,8], and that study revealed radioactive cesium was anomalously localized in that area[9]. In the core sampling survey, the concentration of radioactive cesium varied among the fractionated subsamples even after the homogenized mixing process. This variation indicated the existence of highly concentrated spots; subsequently, radioactive particles were isolated from the sediment samples[10].

Such cesium-enriched particles (cesium particles hereafter) were found on land soon after the accident[11-13]. It is estimated that the cesium fallout immediately after the accident was mainly due to cesium-rich micro particles[14]. The existence of uranium[15-17] and plutonium[18,19] in the particles has also been reported. These findings are important, because such particles are expected to include information about the reactor core, such as evidence of molten core-concrete interaction.

In particular, the cesium particles are classified into two types[20]. Type A has a small size $(1 \sim 10 \mu \mathrm{m})$ with a large ${ }^{134} \mathrm{Cs} /{ }^{137} \mathrm{Cs}$ ratio $(\sim 1.04)$, and Type B is large $(70 \sim 400 \mu \mathrm{m})$ with a small ${ }^{134} \mathrm{Cs} /{ }^{137} \mathrm{Cs}$ ratio $(\sim 0.93)$. The previous experiments suggested that type A particles are distributed widely in marine sediment, and $9 \sim 64 \%$ of cesium is composed of this type of particle[21]. The amount of these particles is relatively large, and their distribution can be approximated as locally uniform. In fact, the radioactivity concentration did not change even when the samples were measured after dividing them into five pieces of $15 \mathrm{~g}$ each[21]. Therefore, type A particles are not a concern in this study because it does not directly affect the results of the wide-area surveys using the towed spectrometer. On the contrary, type B particles could have significant radioactivity and are unevenly distributed. Consequently, the reproducibility of the towed spectrometer measurements possibly decrease if the spectrometer falsely detects an anomaly by the type B particles.

This study aims to reveal the distribution of such cesium particles for the estimation of the effect on the towed spectrometer, and to analyze the characteristics of the particles in marine sediment. First, the distribution of the cesium particles was measured. Next, the particles were isolated from the sediment, and then their composition and structure were analyzed. Finally, the influence of the particles on the towed spectrometer measurement was estimated.

\section{Methods}

\subsection{Particle distribution measurement}

The spatial resolution of the towed gamma-ray detector used in the past work is larger than a few meters at least[7], and it is not suitable for the detection of small radioactive particles. Therefore, a remotely operated vehicle (ROV), MITSUI RTV series (hereafter called RTV) built by the Mitsui Engineering \& Shipbuilding (MES) was adopted. In this study, a special version of RTV customed by MES, Tokyo University, and National Maritime Research Institute was used. RTV has various sensors, for example, gamma-ray detector and imaging sonar. The specification is listed in Table 
Table 1. RTV specification

\begin{tabular}{ll} 
Dimension & $: 1590 \times 890 \times 965 \mathrm{~mm}$ \\
Weight & $: 200 \mathrm{~kg}($ dry weight $)$ \\
Speed & $: 4.6 \mathrm{~km} / \mathrm{h}$ \\
Video output & $:$ HD-SDI \\
Sensors & $:$ gamma-ray spectrometer $(6 \phi \times 3$ inch $\mathrm{NaI}(\mathrm{Tl}))$, forward-looking sonar, \\
& azimuth sensor, depth sensor, temperature and conductivity sensor \\
Instruments & $\begin{array}{l}6 \times \text { LED lighting, } 6 \times \text { thruster, HD TV camera } \\
\text { Global Acoustic Positioning System }(\mathrm{GAPS}),\end{array}$ \\
& sediment sampler, sampler monitor camera \\
\hline
\end{tabular}

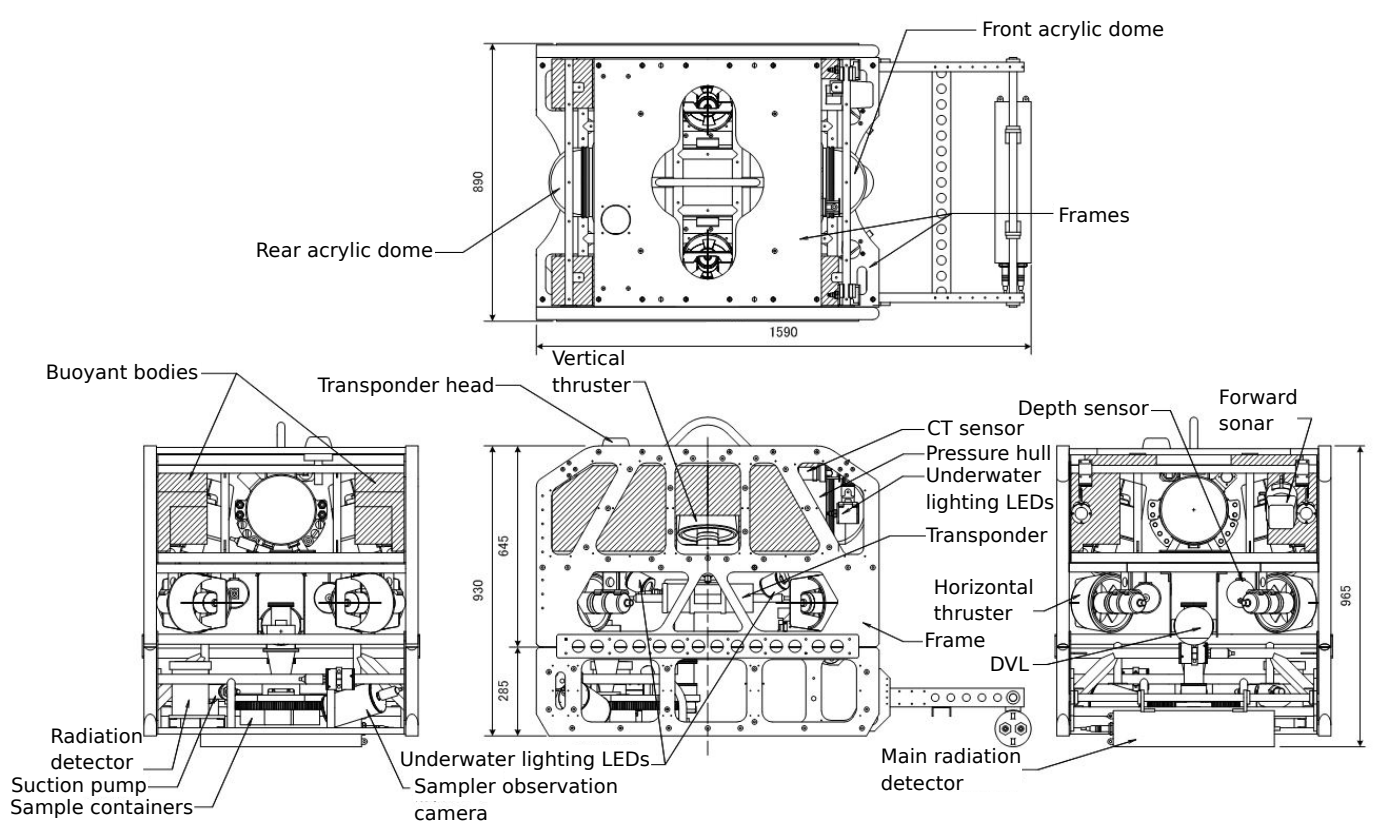

Figure 1. RTV orthographic views.

1. An overview of RTV is shown in Figure 1. The position, gamma-ray spectrum, temperature, and depth data are recorded and transferred in real time to the mother ship every second through an Ethernet cable. Its location was determined by shipboard GPS and acoustic communication with the mother ship. The ROV was handled by an operator with the help of acoustic and optical images, and it was operated at less than $1 \mathrm{~ms}^{-1}$ to scan the seafloor's surface with the gamma-ray detector.

\subsection{Sediment sampling and separating particles}

The radioactive cesium particles were collected to confirm their characteristics, such as shape, radioactivity magnitude, and composition. The sediment sampling was conducted in the Fukushima coastal waters and offshore. Two sampling methods were adopted for this purpose: suction with a pump on the ROV and using multiple corers on the ship. The suction-type sediment sampler was installed on the ROV, as described in the previous section. During the deployment of the ROV, if the count rate of the gamma-ray detector increased significantly (more than approximately a factor of ten), the sediment around the detector was collected and stored in a container. The revolving sediment tank enabled sampling operations at multiple locations during 
Table 2. Locations of the anomalies. The units of latitude and longitude are degrees.

\begin{tabular}{cccc}
\hline & Latitude & Longitude & Depth $(\mathrm{m})$ \\
Anomaly B1 & 37.42309 & 141.06896 & 22 \\
Anomaly B2 & 37.42823 & 141.06995 & 23 \\
Anomaly D1 & 37.41325 & 141.05139 & 16 \\
\hline
\end{tabular}

the gamma-ray survey. For the wide-area sampling survey, 20 locations were selected within the range of $20 \mathrm{~km}$ around NPP1. A conventional multi-core sampler was used, and about $1 \mathrm{~kg}$ of surface sediment $(0-10 \mathrm{~cm})$ was collected on each location.

The radioactive cesium particles were extracted from the sediment samples as follows. First, the sample was fractionated so that the weight of each subsample was less than $150 \mathrm{~g}$. Second, their radioactivity were measured, and the sample was marked if its radioactivity is larger by three times the measuring error compared with the original. Third, the marked samples were divided again, and this procedure was repeated until the radioactive particles could be identified.

\subsection{Electron microscopy analysis}

The obtained particles were analyzed by electron microscopy. First, the particles were coated by carbon using the ion beam deposition method to avoid charging effects. Next, surface backscattering electron images (BEIs) were acquired using a scanning electron microscope (SEM; JSM 7100F by JEOL Ltd.). Subsequently, the particles were cut by focused ion beam milling to analyze their internal structures. Finally, the BEI and element mapping by energy-dispersive X-ray spectrometry (EDS; JED-2300 by JEOL Ltd.) in the cross-sections were acquired.

\section{Results and discussion}

\subsection{Particle distribution near Fukushima NPP1}

Three locations near the Fukushima NPP1 were surveyed by the ROV in November, 2016. It was considered that many cesium particles existed there, because anomalies had been observed in the previous study[9]. The locations of anomalies are tabulated in Table 2, and the complete survey lines are shown in Figure 2.

The logger equipped on the ROV records the pulse height distribution of the $\mathrm{NaI}(\mathrm{Tl})$ scintillation counter and its total count every second. The sediment was obtained by the suction-type sampler at the places where the total counting rate drastically increased. After acquiring a certain number of samples, the ROV surfaced and was returned to the sea after exchanging the sample containers. Therefore, the survey line has discontinuities. Because the survey line around the anomaly B had a large discontinuity, it was separated into two parts, "B1" and "B2." The sampled points and total counting rate along the survey lines are shown in Figures 3, 4, and 5.

The positions of the cesium particles were estimated. It was assumed that the cesium particles exist at the locations where the total counting rate increased by more than eight times its statistical error, considering past experiments of cesium particle survey and removal[23]. The presence of the cesium particles estimated by this criterion is shown in Figures 6, 7, and 8. Note that the scales of the horizontal and vertical axes of Figure 8 are several times larger than those of the others. 


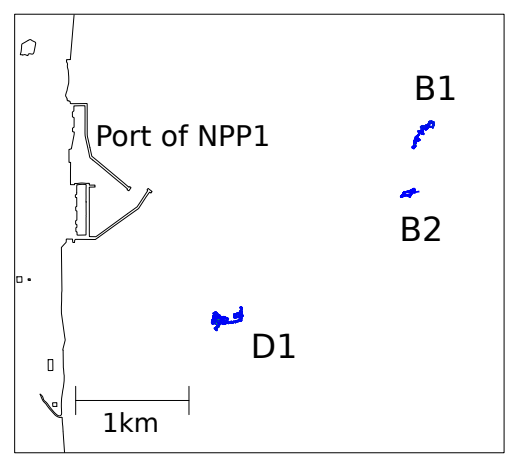

Figure 2. Survey lines of the ROV in front of Fukushima NPP1. The geographical data are adopted from the database of the Geospatial Information Authority of Japan[22].

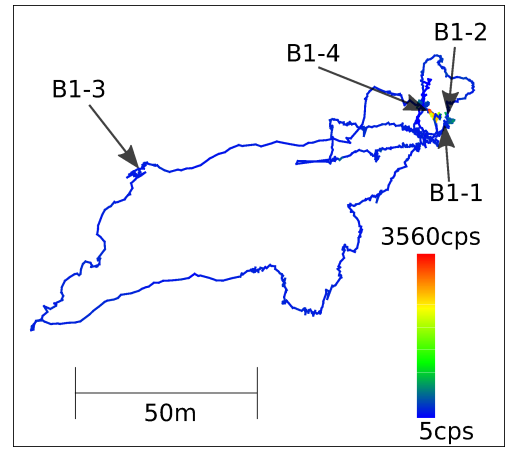

Figure 3. Counting rate distribution and sampled points on the survey line B1.

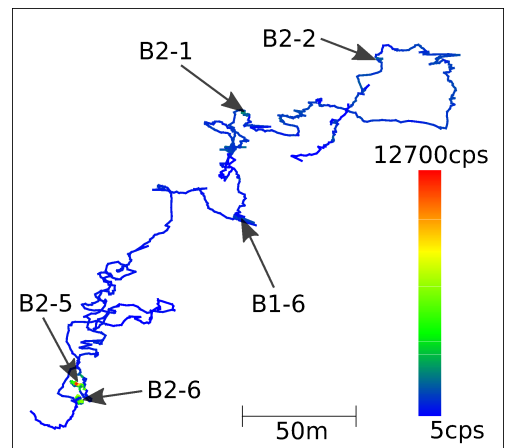

Figure 4. Counting rate distribution and sampled points on the survey line B2.

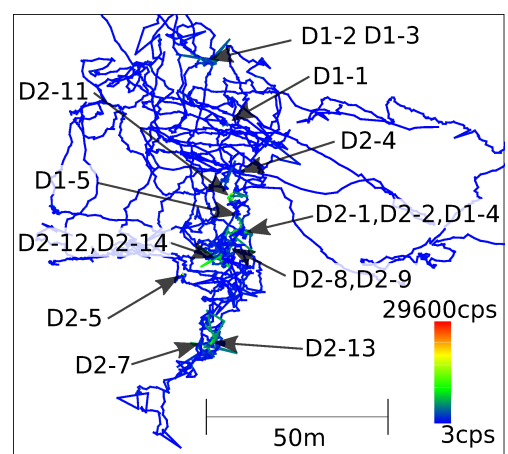

Figure 5. Counting rate distribution and sampled points on the survey line D1. 


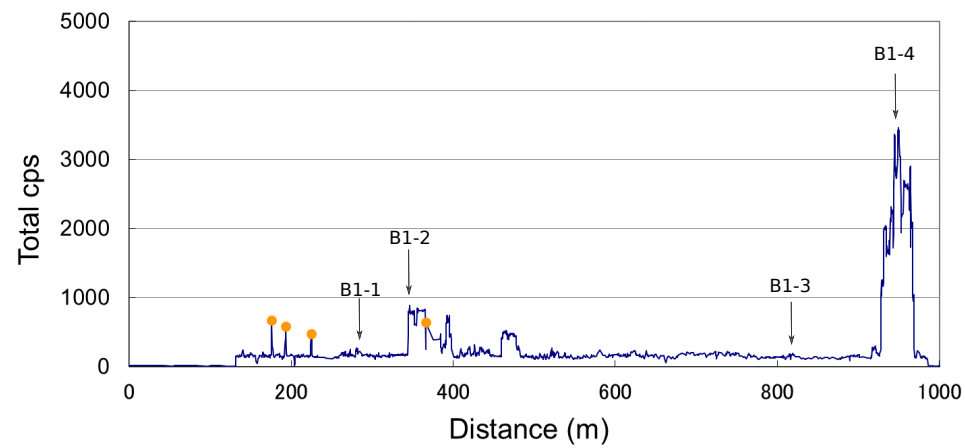

Figure 6. Counting rate distribution (blue line) and estimated particle positions (orange points) on the survey line B1. The arrows indicate the sampled points.

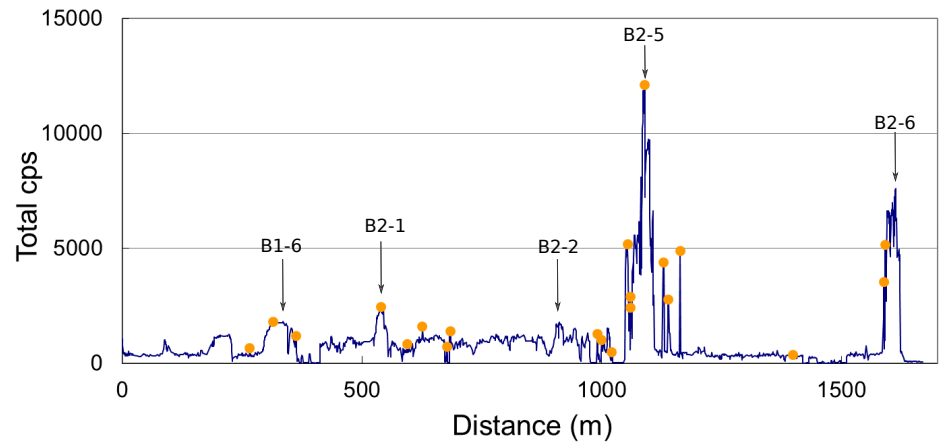

Figure 7. Counting rate distribution (blue line) and estimated particle positions (orange points) on the survey line B2. The arrows indicate the sampled points.

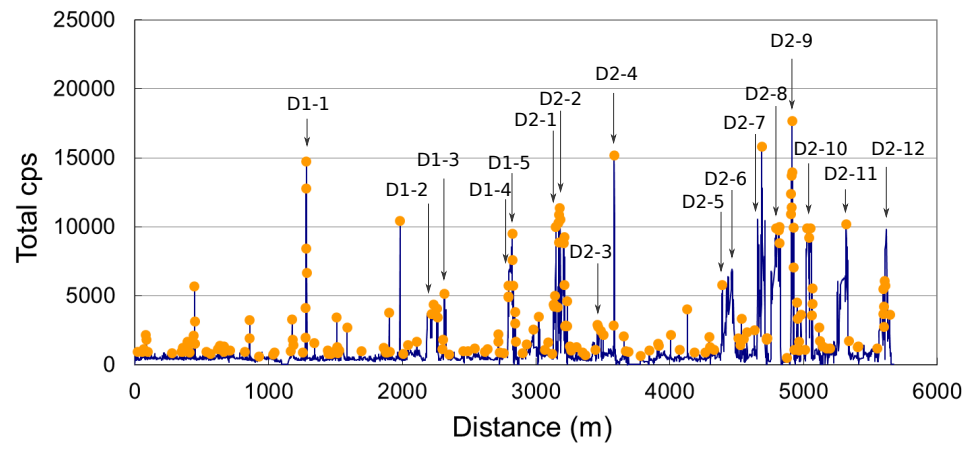

Figure 8. Counting rate distribution (blue line) and estimated particle positions (orange points) on the survey line D1. The arrows indicate the sampled points. 
Table 3. The numbers of particles per meter and their influence on the total counting rate on the survey lines, B1, B2, D1.

\begin{tabular}{lccc}
\hline Survey line & B1 & B2 & D1 \\
\hline $\begin{array}{c}\text { Number of particles per } \\
\text { meter (particles } / \mathrm{m} \text { ) }\end{array}$ & $3.91 \times 10^{-3}$ & $1.26 \times 10^{-2}$ & $3.45 \times 10^{-2}$ \\
$\begin{array}{c}\text { Average increasing rate } \\
\text { on the particle }(\%)\end{array}$ & +86 & +58 & +67 \\
\hline $\begin{array}{l}\text { a } \\
\text { These rates were calculated by averaging the counting rate ratios above }\end{array}$ \\
$\begin{array}{l}\text { the particle to background over all the particles. The background means } \\
\text { counting rate averaged over a 20-m range. }\end{array}$
\end{tabular}

The number of particles found on each survey line per meter and the average increase in counting rate right above the particle are summarized in Table 3 . There ought to be only one particle per 29 meters (inverse of $3.45 \times 10^{-2}$ ), even on the survey line D1; moreover, the increase in the counting rate is approximately $86 \%$ on average on the survey line B1.

Here, turning now to the effect of Cs particles on the wide-area survey, we estimated the change in the counts of a towed spectrometer with the same detector as that on the ROV. Because the mean free path of a $662 \mathrm{keV}$ photon from ${ }^{137} \mathrm{Cs}$ in water is approximately $13 \mathrm{~cm}$, the spectrometer is assumed to be affected within a radius of 13 $\mathrm{cm}$ around the particle for simplicity. In this range, the Cs particles increase the count rate by the value shown in Table 3 . Provided that the spectrometer is towed on the survey line D1, 1.67 times the counting rate is expected (see column D1 in Table 3) in a section of $26 \mathrm{~cm}$ while towing $29 \mathrm{~m}$. Therefore, the contribution from a particle is estimated to be $1.5 \%(0.26 / 29 \times 1.67=0.015)$ in average. This value is by far smaller than the towed spectrometer's uncertainty, typically few tens of percent[8].

\subsection{Cesium particle extraction}

The ${ }^{137}$ Cs concentration of the sediment samples obtained by the ROV is shown in Figure 9. All the samples weighed less than $200 \mathrm{~g}$ and were divided into more than five pieces. The segmented samples for which the radioactivity was higher than the average value by three times the statistical error were considered to contain cesium particles. These were subdivided and measured repeatedly until the cesium particles were identified. Three particles from the sample B2-6, designated "B2-p1," "B2-p2," and "B2-p3," and one particle from D1-5 named "D1-p1" were extracted as a result. Totally 4 particles were collected from 25 samples. The ROV does not have any methods to confirm whether the radioactive particle is collected because the surface of the sediment in contact with the detector is dug and mixed once the suction sampler is activated. Hence, not all particles detected by the ROV could be collected.

Furthermore, to measure the distribution of cesium particles off the coast of Fukushima, conventional sediment sampling with a multicore sampler was conducted at the same time. In the investigation, $1 \mathrm{~kg}$ of surface sediment was collected up to $20 \mathrm{~km}$ offshore of NPP1 at intervals of approximately $5 \mathrm{~km}$. The sampled locations are shown in Figure 10. A total of $24 \mathrm{~kg}$ of sediment was obtained, and one particle, "C1-p1," was extracted from the sample obtained at the point C1 in Figure 10.

The ${ }^{137} \mathrm{Cs}$ radioactivity values of those particles measured by the high-purity germanium detector are shown in Table 4. No significant peaks were observed except for those caused by ${ }^{134} \mathrm{Cs},{ }^{137} \mathrm{Cs}$, and natural radioactive nuclides. Considering from the 


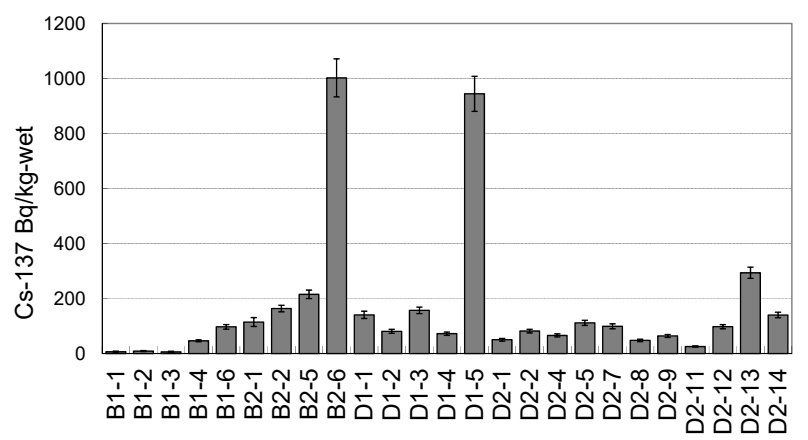

Figure 9. ${ }^{137} \mathrm{Cs}$ radioactivity of the sediments sampled by the ROV's suction sampler. The error bars denote the standard deviation.

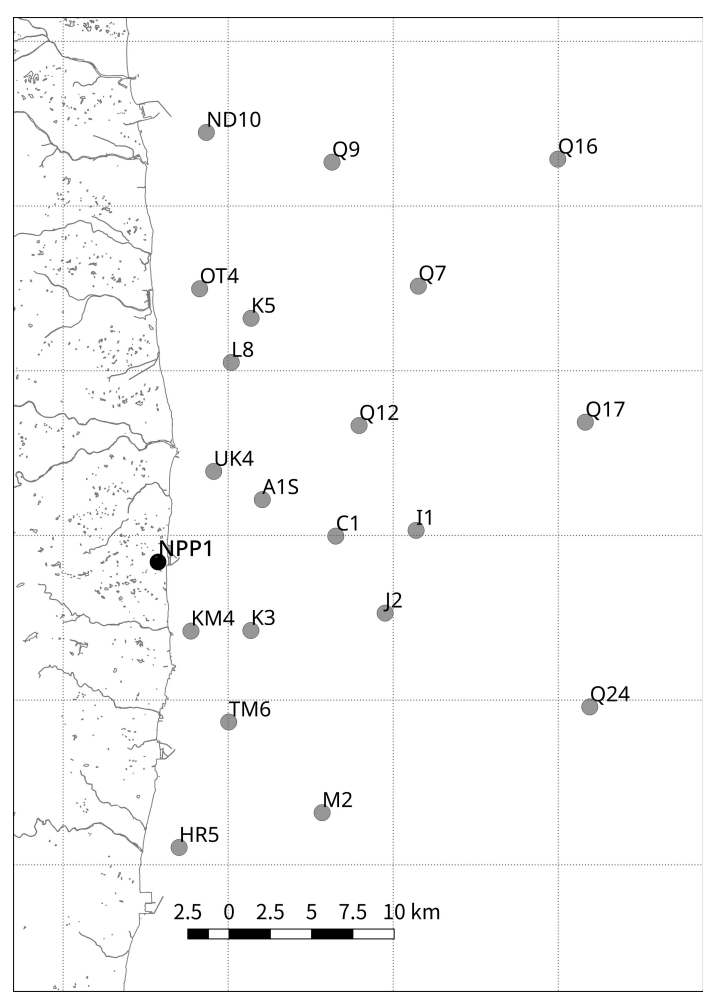

Figure 10. Sediment sampling points by the multicore sampler. The geographical data are adopted from the database of the Geospatial Information Authority of Japan[22]. 
Table 4. Extracted cesium particles. Numbers in parentheses indicate error $(1 \sigma$, unit:\%). All values have been corrected to the ones at the time of the accident.

\begin{tabular}{lccc}
\hline Particle & ${ }^{137} \mathrm{Cs} \mathrm{Bq}$ & ${ }^{134} \mathrm{Cs} /{ }^{137} \mathrm{Cs}$ ratio & Method \\
\hline B2-p1 & $317(2.1)$ & $0.95(7.8)$ & ROV \\
B2-p2 & $17.9(2.3)$ & $0.95(10)$ & $"$ \\
B2-p3 & $5.09(2.9)$ & $0.92(16)$ & $"$ \\
D1-p1 & $93.7(0.9)$ & $0.98(5.7)$ & $"$ \\
C1-p1 & $356(2.1)$ & $0.92(5.2)$ & core sampler \\
\hline
\end{tabular}
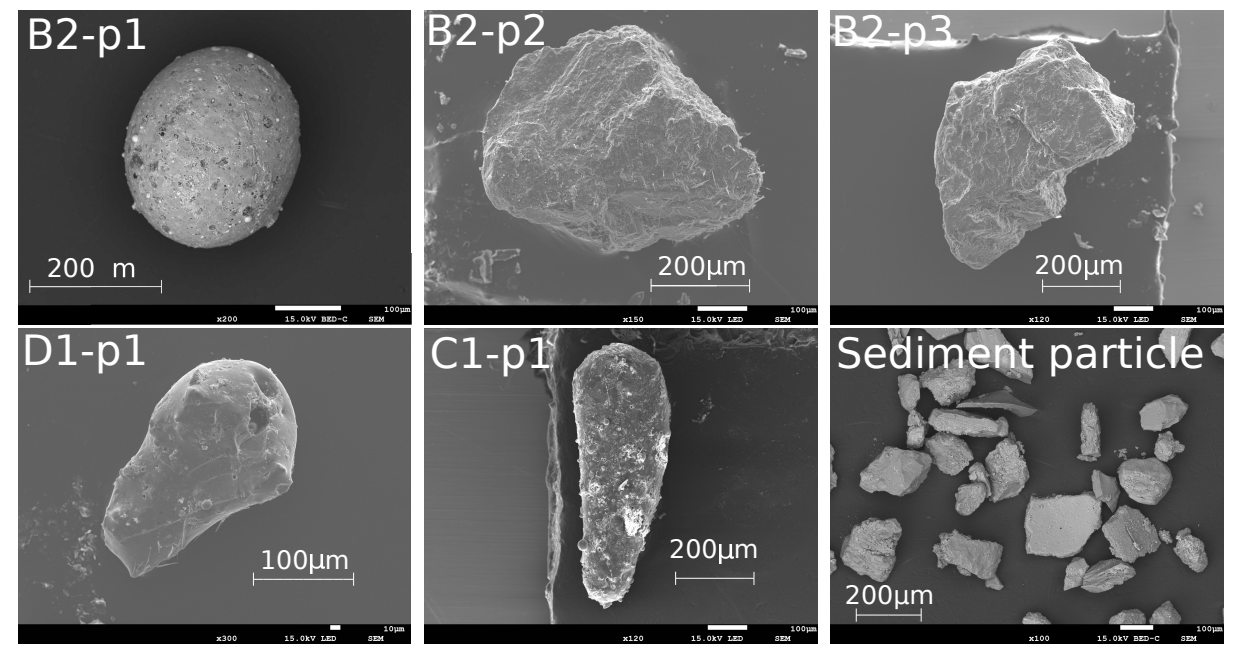

Figure 11. BEIs of the cesium particles and non-radioactive sediment particles.

cesium ratios, these particles are classified as type B particles reported in previous work[20]. Though the accuracy of ${ }^{134} \mathrm{Cs}$ radioactivity is not enough for particles with low radioactivity due to the influence of the background radiation, this classification is consistent with that by the particle size obtained from the electron microscope images described in the next section.

\subsection{Electron microscopy analysis}

The cesium particles were analyzed by electron microscopy; the BEIs of the particles are shown in Figure 11. This figure also includes that of normal sediment in the B2-6 sample for comparison. The particles were classified into smooth spherical shapes (B2-p1, D1-p1, C1-p1) and rough shapes (B2-p2, B2-p3). The smooth particles have spherical protrusions on the surface, and their radioactivity is relatively large. In contrast, rough particles are similar in shape to non-radioactive sediment particles, and their radioactivity is small. For typical cases of the former and the latter, sectional element mapping images of B2-p1 and B2-p2 are shown in Figures 12 and 13, respectively. The other particles' data are included in Appendix A.

B2-p1 was possibly produced in a high-temperature environment, as evidenced by its spherical internal voids. Its surface protrusions consist of calcium and titanium oxide. The interior is separated into two parts, one with the same composition as that of the protrusions and the other with silicon oxide. The Table 5 shows the main compositions on each spot measured by electron probe micro analysis. These characteristics are common to the other smooth particles, D1-p1 and C1-p1 (see Appendix A). The 

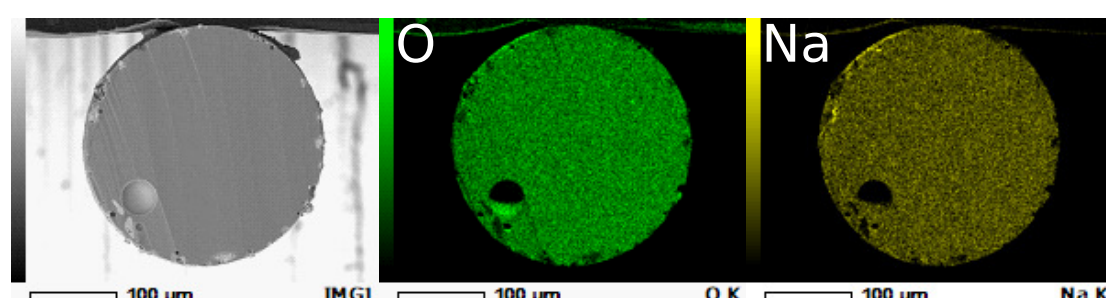

$\mathrm{Mg}$
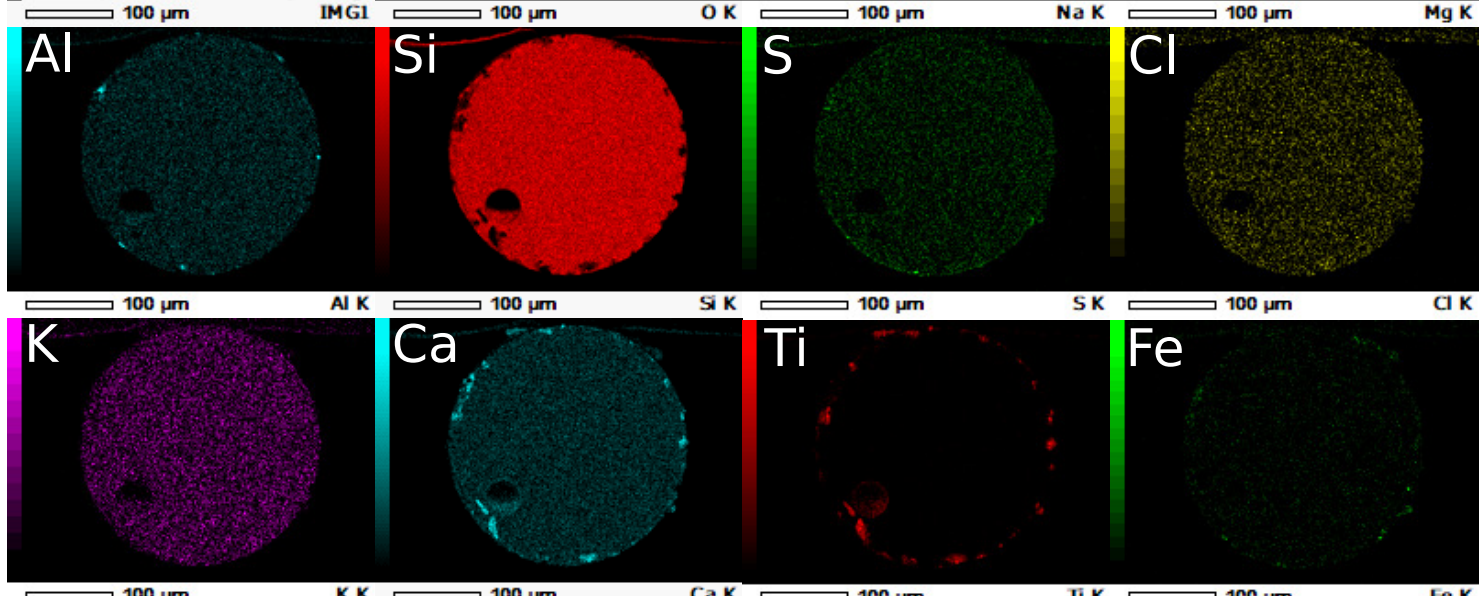

Figure 12. Sectional element mapping image of the B2-p1 particle.
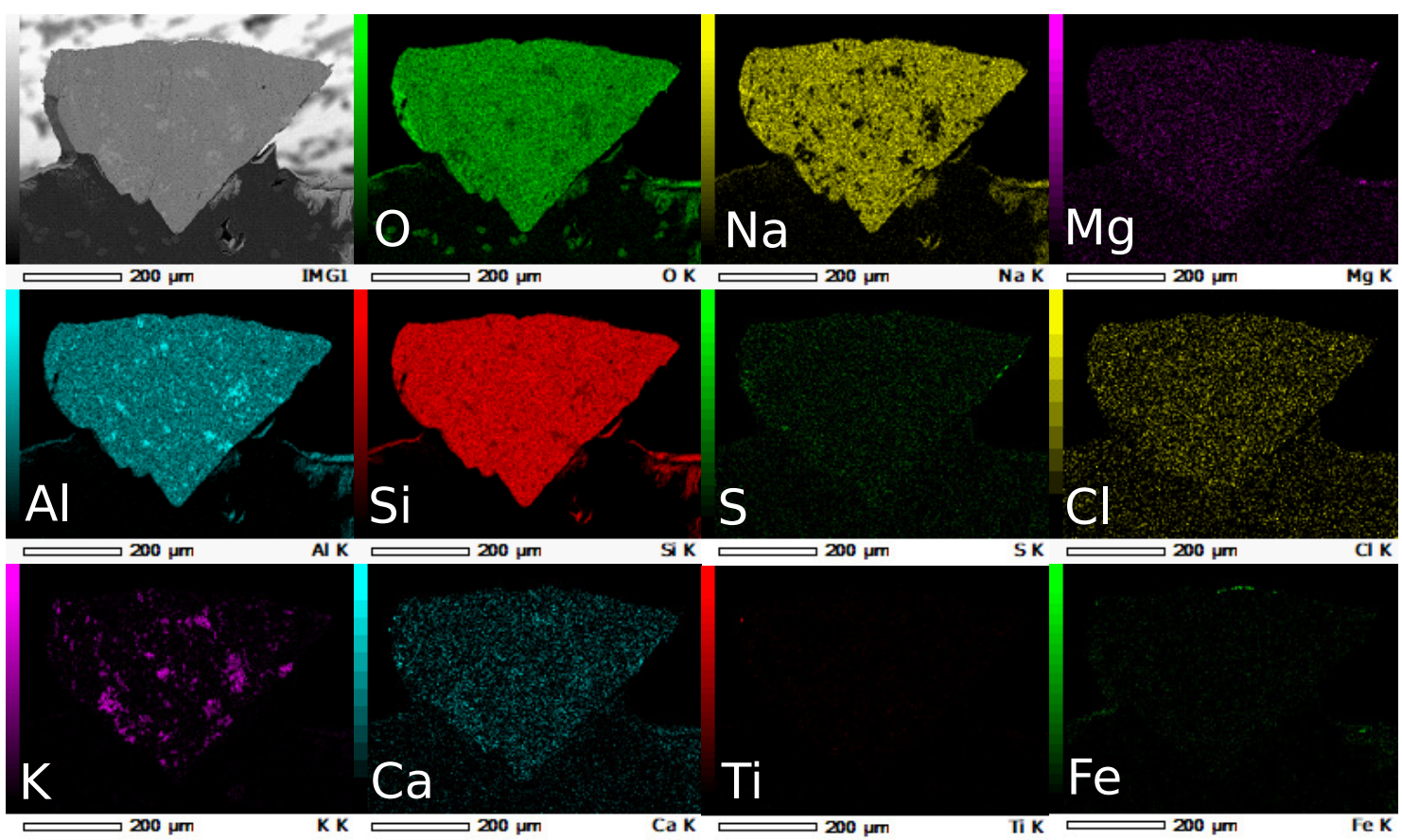

Figure 13. Sectional element mapping image of the B2-p2 particle. 
Table 5. Elemental compositions (number ratio, unit:\%)

\begin{tabular}{cll}
\hline Element & Ti spot & Other part \\
\hline $\mathrm{O}$ & 64 & 74 \\
$\mathrm{Mg}$ & 0.18 & \\
$\mathrm{Al}$ & 0.71 & 1.3 \\
$\mathrm{Si}$ & 1.5 & 25 \\
$\mathrm{Cl}$ & 0.14 & 0.075 \\
$\mathrm{Ca}$ & 17 & \\
$\mathrm{Ti}$ & 16 & 0.03 \\
$\mathrm{Fe}$ & 0.71 & \\
$\mathrm{~K}$ & & 0.091 \\
\hline
\end{tabular}

interiors of B2-p2 are nearly homogeneous silicon, sodium, and aluminum oxides dotted with potassium. A tiny titanium spot is also present on the B2-p2 surface, and there is no remarkable internal structure. These observation data imply that radioactive cesium is contained together with titanium and calcium.

\subsection{Discussion}

The fuel compositions of each unit in NPP1 had been estimated[24] by the ORIGEN22UPJ code[25] from the burnup histories. Based on this data, the dispersion of radioactive materials from each unit has been grasped by the the ${ }^{134} \mathrm{Cs} /{ }^{137} \mathrm{Cs}$ ratio, and it is shown that radioactive cesium released from Unit 1 flowed toward the northnorthwest[26-28]. The wind at the time of the wet venting and hydrogen explosion of Unit 1 (12th March 15:36 JST) was blowing north-northwest, and then, from early morning on the 13th to the night of the 14th, the wind was blowing eastward[28]. Therefore, large amount of radioactive materials was released eastward at that time. The reverse estimation method using atmospheric and marine simulation evaluated that $32 \%$ of ${ }^{137} \mathrm{Cs}$ was released by the plume flowed toward the Pacific Ocean[29]. The C1-p1 particle is considered to be the fallout of the plume because it was collected $10 \mathrm{~km}$ offshore of NPP1 and the north-south ocean current is predominant in that area[30]. It is not clear whether the other particles were deposited from the plume or were contained in the contaminated water because they were found near the NPP1.

In addition to the ${ }^{134} \mathrm{Cs} /{ }^{137} \mathrm{Cs}$ ratio, the study that focused on ${ }^{110 \mathrm{~m}} \mathrm{Ag}$, which is emitted more at higher temperatures, suggested a decrease in the temperature of Unit 2 due to the cooling operation[26]. This is consistent with the fact that type B particles emitted from Unit 1 may have internal cavities originating from high temperatures[31]. Judging from the shape, internal structure, and cesium ratio, B2-p1, D2-p1, and C1p1 are clearly classified as type B. Although B2-p2 and B2-p3 particles were also presumed to originate from Unit 1 considering the ${ }^{134} \mathrm{Cs} /{ }^{137} \mathrm{Cs}$ ratio, their composition and structure are the same as sediment particles. Therefore, it is probable that these particles were formed by adhering cesium to the concrete aggregate or sediment. No radioactive nuclides derived from the fuel, e.g., uranium and plutonium, were found by the gamma spectrometry nor the electron microscopy analysis. However, in recent studies, uranium[32] and plutonium[18] are detected even in type B particles.

Therefore, it is possible that these elements are detected in the particles extracted from marine sediment by using high sensitive analysis. More detailed investigation is needed to obtain information on fuel debris from these particles. 


\section{Conclusion}

In this study, cesium particle distribution was measured near NPP1 with an ROV. This investigation revealed that the average cesium particle concentration was approximately $0.13 \mathrm{~m}^{-2}$ at most assuming that the detection range was $0.26 \mathrm{~m}$ wide (equivalent to twice the mean free path of a ${ }^{137} \mathrm{Cs} 662-\mathrm{keV}$ photon). Considering the frequency of encountering particles and change in the total counting rate, it is concluded that the influence of the particles on the macroscopic radioactive cesium distribution is limited.

Sediment samples were obtained by the suction-type sampler of the ROV and by the multicore sampler. Subsequently, five cesium-enriched particles were isolated. Titanium and calcium were commonly detected in the particles with high radioactivity. Previous papers have reported the presence of calcium and titanium in B-type particles[20,32], and these elements are found to be locally distributed near the surface in the B2-p1, D2-p1, and C1-p1 particles. The silicon oxide in the particle is estimated to originate from heat insulating materials[20] or the concrete pedestal[15] in the reactor; however, the source of the titanium is unclear. Not all the particles on the survey lines were collected, and it is possible that the other types of radioactive particles exist near NPP1. To improve the collection efficiency, the capability of the sample tank should be expanded.

Because the cesium particles are insoluble, they are excreted even if incorporated into the body. Because they are retained in the lungs in the case of particle inhalation, the effects of long-term internal exposure have been investigated[33]. However, insoluble particles in water or sediment rarely reach the lungs. External exposure is also not expected because the gamma rays from the particle are shielded by water. Therefore, there is little apparent need to adopt urgent measures to address the risks due to the cesium particles.

\section{Acknowledgements}

The authors thank Masashi Kusakabe (Marine Ecology Research Institute) and Shunichi Hisamatsu (Institute for Environmental Science) for valuable advice on our research plan. The authors are particularly grateful for the persistent support at sea provided by Fukushima-Ken Fisheries Cooperative Association and Sanyo Technomarine. Without the help of Hakuyodo and Azumino Electric Components in constructing the instruments, the suction-type sampler would not have been completed.

\section{Funding}

This study was supported by SENTAN.JST, and funded by the Nuclear Regulation Authority of Japan through the survey project for the distribution of radioactive materials in Fukushima coastal waters in the fiscal year 2016.

\section{References}

[1] Tsumune D, Tsubono T, Aoyama M, et al. Distribution of oceanic ${ }^{137} \mathrm{Cs}$ from the Fukushima Dai-ichi Nuclear Power Plant simulated numerically by a regional ocean 
model. Journal of Environmental Radioactivity. 2012 Sep;111:100-108. Available from: https://linkinghub.elsevier.com/retrieve/pii/S0265931X11002463.

[2] Kawamura H, Kobayashi T, Furuno A, et al. Preliminary Numerical Experiments on Oceanic Dispersion of ${ }^{131} \mathrm{I}$ and ${ }^{137} \mathrm{Cs}$ Discharged into the Ocean because of the Fukushima Daiichi Nuclear Power Plant Disaster. Journal of Nuclear Science and Technology. 2011 Nov;48(11):1349-1356. Available from: http://www.tandfonline.com/doi/abs/ 10.1080/18811248.2011.9711826.

[3] Kanda J. Continuing ${ }^{137}$ Cs release to the sea from the Fukushima Dai-ichi Nuclear Power Plant through 2012. Biogeosciences. 2013 Sep;10(9):6107-6113. Available from: https: //bg. copernicus .org/articles/10/6107/2013/.

[4] Machida M, Yamada S, Iwata A, et al. Seven-year temporal variation of Caesium-137 discharge inventory from the port of Fukushima Daiichi Nuclear Power Plant: continuous monthly estimation of Caesium-137 discharge in the period from April 2011 to June 2018. Journal of Nuclear Science and Technology. 2020 Aug;57(8):939-950. Available from: https://www . tandfonline.com/doi/full/10.1080/00223131.2020.1740809.

[5] Nuclear Regulation Authority. Radioactivity concentration in the seawater near Fukushima Dai-ichi NPP (Daily) (SamplingData: Jul 19-25.2020) ; 2020. Available from: https ://radioactivity.nsr.go.jp/en/contents/15000/14325/24/278_4_ 20200728.pdf.

[6] Nuclear Regulation Authority. Change of the radioactivity concentration of the sediment in sea area close to Fukushima Daiich NPS / coastal sea area ; 2020. Available from: https://radioactivity.nsr.go.jp/en/contents/8000/7747/24/engan_soil.pdf.

[7] Thornton B, Ohnishi S, Ura T, et al. Continuous measurement of radionuclide distribution off Fukushima using a towed sea-bed gamma ray spectrometer. Deep-Sea Res Part I: Oceanogr Res Pap. 2013 May;79:10-19. Available from: http://www.sciencedirect. com/science/article/pii/S0967063713000915.

[8] Ohnishi S, Thornton B, Kamada S, et al. Conversion factor and uncertainty estimation for quantification of towed gamma-ray detector measurements in Tohoku coastal waters. Nuclear Instruments and Methods in Physics Research Section A: Accelerators, Spectrometers, Detectors and Associated Equipment. 2016 May;819:111-121. Available from: http://linkinghub.elsevier.com/retrieve/pii/S0168900216002412.

[9] Thornton B, Ohnishi S, Ura T, et al. Distribution of local ${ }^{137} \mathrm{Cs}$ anomalies on the seafloor near the Fukushima Dai-ichi Nuclear Power Plant. Mar Pollut Bull. 2013 Sep;74(1):344-350. Available from: http://www.sciencedirect.com/science/ article/pii/S0025326X13003378.

[10] Ohnishi S, Koike T, Kamada S, et al. Analysis of cesium-bearing micro particles in the sediment samples obtained by a ROV in Fukushima coastal waters (in Japanese). In: Proceedings of Atomic Energy Society Japan 2016 Fall Meeting; Sep.; Kurume; 2016.

[11] Adachi K, Kajino M, Zaizen Y, et al. Emission of spherical cesium-bearing particles from an early stage of the Fukushima nuclear accident. Scientific Reports. 2013 Dec;3(1). Available from: http://www. nature.com/articles/srep02554.

[12] Satou Y, Sueki K, Sasa K, et al. First successful isolation of radioactive particles from soil near the Fukushima Daiichi Nuclear Power Plant. Anthropocene. 2016 Jun;14:71-76. Available from: https://linkinghub.elsevier.com/retrieve/ pii/S2213305416300340.

[13] Yamaguchi N, Mitome M, Kotone AH, et al. Internal structure of cesium-bearing radioactive microparticles released from Fukushima nuclear power plant. Scientific Reports. 2016 Apr;6(1). Available from: http://www.nature.com/articles/srep20548.

[14] Utsunomiya S, Furuki G, Ochiai A, et al. Caesium fallout in Tokyo on 15th March, 2011 is dominated by highly radioactive, caesium-rich microparticles. arXiv:190600212 [physics]. 2019 Jul;ArXiv: 1906.00212; Available from: http://arxiv.org/abs/1906.00212.

[15] Furuki G, Imoto J, Ochiai A, et al. Caesium-rich micro-particles: A window into the meltdown events at the Fukushima Daiichi Nuclear Power Plant. Scientific Reports. 2017 Mar;7(1). Available from: http://www. nature.com/articles/srep42731. 
[16] Ochiai A, Imoto J, Suetake M, et al. Uranium Dioxides and Debris Fragments Released to the Environment with Cesium-Rich Microparticles from the Fukushima Daiichi Nuclear Power Plant. Environmental Science \& Technology. 2018 Mar;52(5):2586-2594. Available from: https://pubs.acs.org/doi/10.1021/acs.est.7b06309.

[17] Ohnuki T, Satou Y, Utsunomiya S. Formation of radioactive cesium microparticles originating from the Fukushima Daiichi Nuclear Power Plant accident: characteristics and perspectives. Journal of Nuclear Science and Technology. 2019 Oct;56(9-10):790-800. Available from: https://www.tandfonline.com/doi/full/10.1080/00223131.2019. 1595767.

[18] Igarashi J, Zheng J, Zhang Z, et al. First determination of $\mathrm{Pu}$ isotopes $\left({ }^{239} \mathrm{Pu},{ }^{240} \mathrm{Pu}\right.$ and ${ }^{241} \mathrm{Pu}$ ) in radioactive particles derived from Fukushima Daiichi Nuclear Power Plant accident. Scientific Reports. 2019 Dec;9(1). Available from: http://www.nature.com/ articles/s41598-019-48210-4.

[19] Kurihara E, Takehara M, Suetake M, et al. Particulate plutonium released from the Fukushima Daiichi meltdowns. Science of The Total Environment. 2020 Nov;743:140539. Available from: https://linkinghub.elsevier.com/retrieve/pii/ S0048969720340614.

[20] Satou Y, Sueki K, Sasa K, et al. Analysis of two forms of radioactive particles emitted during the early stages of the Fukushima Dai-ichi Nuclear Power Station accident. GEOCHEMICAL JOURNAL. 2018;52(2):137-143. Available from: https://www . jstage.jst.go.jp/article/geochemj/52/2/52_2.0514/_article.

[21] Ikenoue T, Ishii N, Kusakabe M, et al. Contribution of ${ }^{137}$ Cs-enriched particles to radiocesium concentrations in seafloor sediment: Reconnaissance experiment. PLOS ONE. 2018 Sep;13(9):e0204289. Available from: https://dx.plos.org/10.1371/journal. pone. 0204289.

[22] Ministry of Land, Infrastructure, Transport and Tourism. Geospatial Information Authority of Japan (GSI) ; 2015. Available from: http://www.gsi.go.jp/ENGLISH/index.html.

[23] Toole J, Innes S. ROV Mapping Surveys Offshore of Dounreay in 2005 and 2006. UK Atomic Energy Authority; 2007. EPD(06)P272.

[24] Nishihara K, Hiroki I, Kenya S. Estimation of Fuel Compositions in FukushimaDaiichi Nuclear Power Plant (in Japanese). Ibaraki: Japan Atomic Energy Agency; 2012. JAEA-DATA/CODE 2012-018. Available from: https://doi.org/10.11484/ jaea-data-code-2012-018.

[25] Kataoka M, Matsumoto H, Ohkawachi Y, et al. ZZ ORLIBJ32 \& ZZ ORIGEN2.2-UPJ, ORIGEN2 libraries based on JENDL-3.2 and JENDL-3.3 ; 2006. Available from: https: //www .oecd-nea.org/tools/abstract/detail/nea-1642.

[26] Satou Y, Sueki K, Sasa K, et al. Classification using ${ }^{110 \mathrm{~m}} \mathrm{Ag} /{ }^{137}$ Cs ratio in high dose area at the northwestern from Fukushima Daiichi nuclear plant (in Japanese). Houshakagaku (in Japanese). 2015;31:28-29.

[27] Nishizawa Y, Yoshida M, Sanada Y, et al. Distribution of the ${ }^{134} \mathrm{Cs} /{ }^{137} \mathrm{Cs}$ ratio around the Fukushima Daiichi nuclear power plant using an unmanned helicopter radiation monitoring system. Journal of Nuclear Science and Technology. 2016 Apr;53(4):468-474. Available from: http://www .tandfonline.com/doi/full/10.1080/00223131.2015.1071721.

[28] Chino M, Terada H, Nagai H, et al. Utilization of ${ }^{134} \mathrm{Cs} /{ }^{137} \mathrm{Cs}$ in the environment to identify the reactor units that caused atmospheric releases during the Fukushima Daiichi accident. Scientific Reports. 2016 Aug;6(1). Available from: http://www.nature.com/ articles/srep31376.

[29] Katata G, Chino M, Kobayashi T, et al. Detailed source term estimation of the atmospheric release for the Fukushima Daiichi Nuclear Power Station accident by coupling simulations of an atmospheric dispersion model with an improved deposition scheme and oceanic dispersion model. Atmospheric Chemistry and Physics. 2015 Jan;15(2):1029-1070. Available from: https://acp.copernicus.org/articles/15/1029/2015/.

[30] Asami M. Topographic Change and associated transport of suspended particulate materials around Fukushima Coast in Japan (in Japanese). Papers of National Maritime 

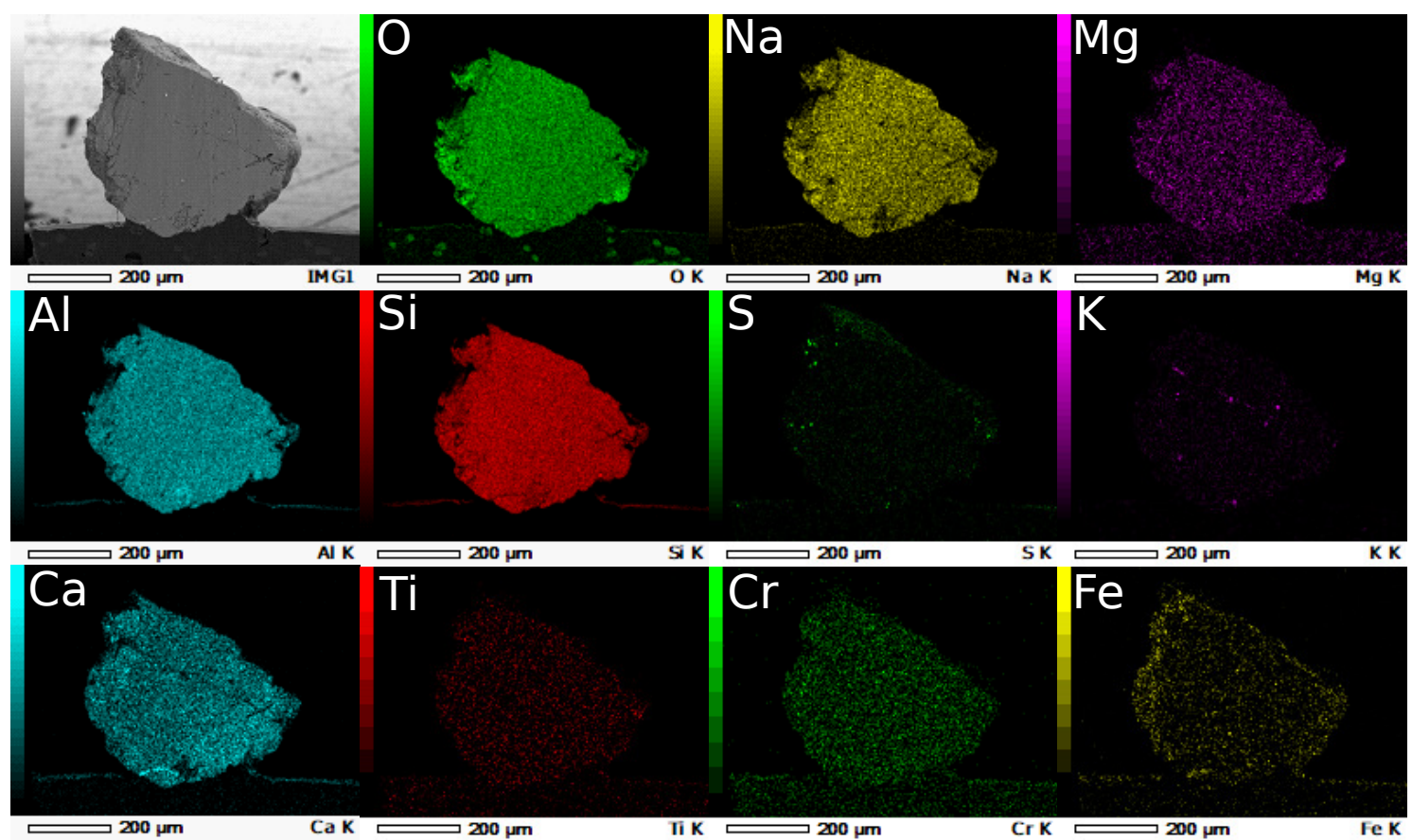

Figure A1. Sectional element mapping image of particle B2-p3.

Research Institute. 2019 Jan;18(2):241-257. Available from: https://www.nmri.go.jp/ _src/21802/PNM22180203-00.pdf.

[31] Martin PG, Louvel M, Cipiccia S, et al. Provenance of uranium particulate contained within Fukushima Daiichi Nuclear Power Plant Unit 1 ejecta material. Nature Communications. 2019 Dec;10(1). Available from: http://www.nature.com/articles/ s41467-019-10937-z.

[32] Ono T, Iizawa Y, Abe Y, et al. Investigation of the Chemical Characteristics of Individual Radioactive Microparticles Emitted from Reactor 1 by the Fukushima Daiichi Nuclear Power Plant Accident by Using Multiple Synchrotron Radiation X-ray Analyses (in Japanese). Bunseki kagaku. 2017;66(4):251-261. Available from: https://www.jstage. jst.go.jp/article/bunsekikagaku/66/4/66_251/_article/-char/ja/.

[33] Manabe K, Matsumoto M. Development of a stochastic biokinetic method and its application to internal dose estimation for insoluble cesium-bearing particles. Journal of Nuclear Science and Technology. 2019 Jan;56(1):78-86. Available from: https://www . tandfonline.com/doi/full/10.1080/00223131.2018.1523756.

\section{Appendix A. EDS images of cesium-enriched particles}



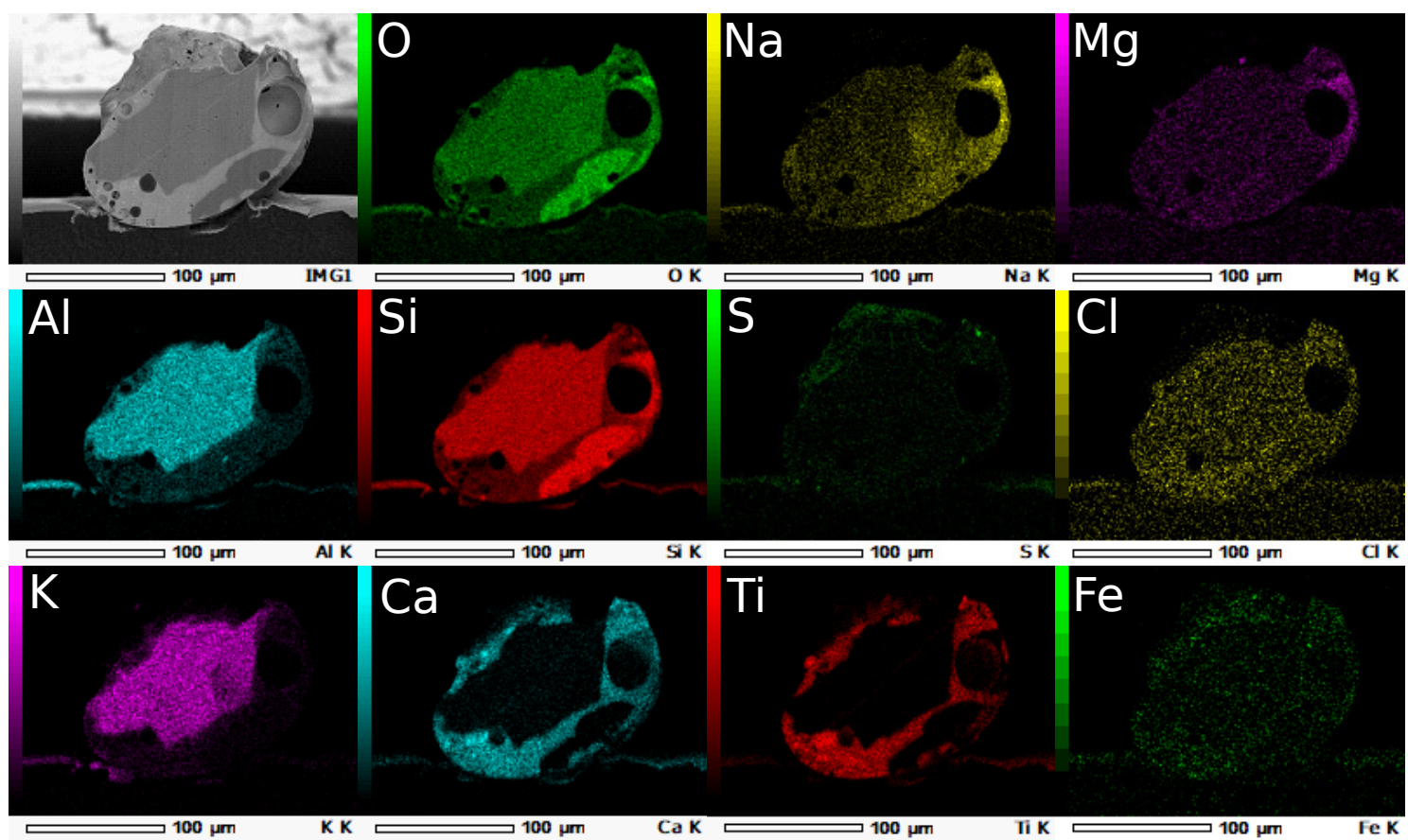

Figure A2. Sectional element mapping image of particle D1-p1.
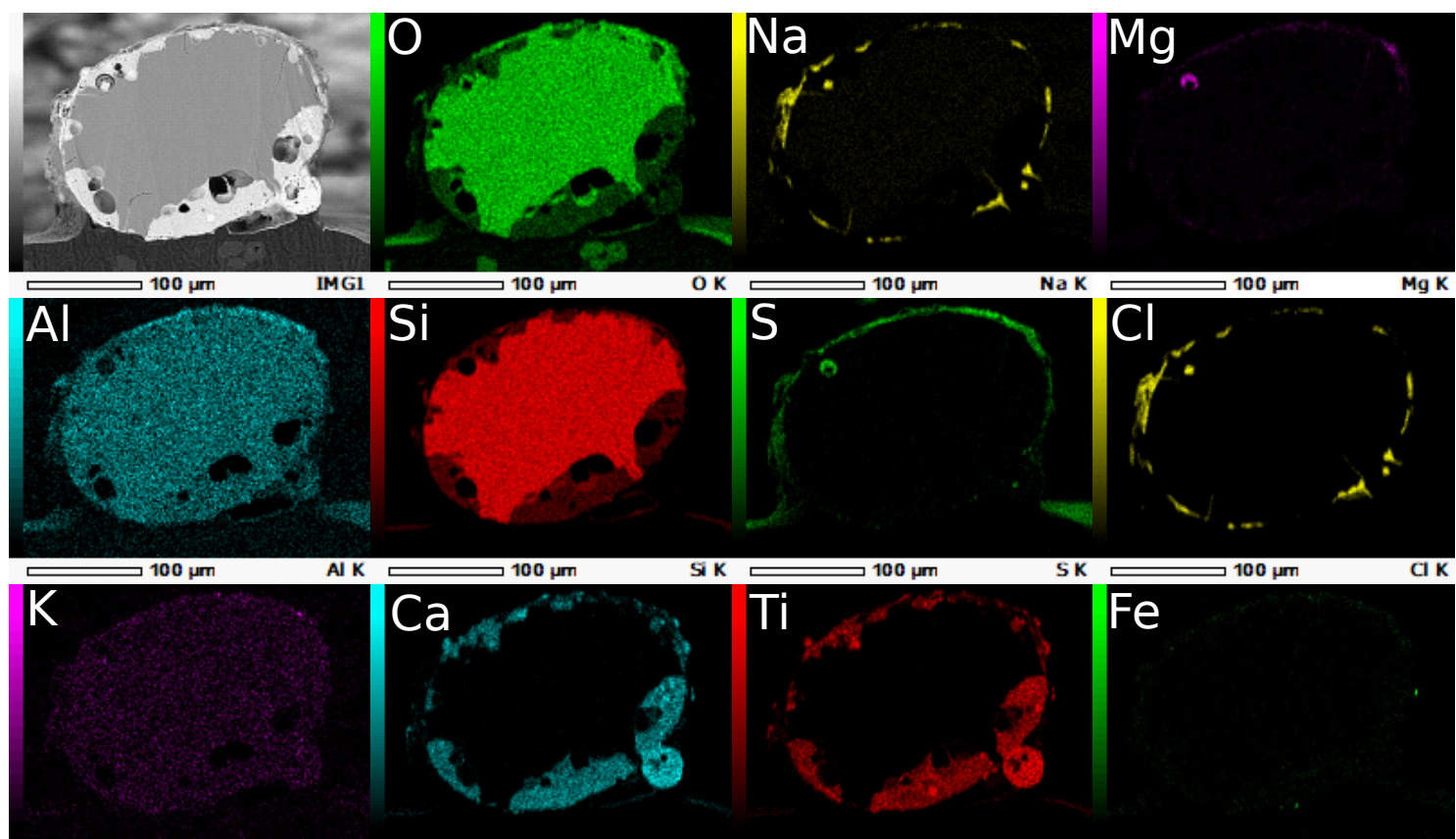

K $100 \mu \mathrm{m}$

K $100 \mu \mathrm{m}$

Cl K

$100 \mu \mathrm{m}$

KK

$\mathrm{CaK} \rightleftharpoons 100 \mu \mathrm{m}$

Ti K ऍ $100 \mu \mathrm{mm}$

Fe K

Figure A3. Sectional element mapping image of particle C1-p1. 